\title{
Diagnostic challenge of artifactual electrocardiographic tachyarrhythmias
}

\author{
S. Serge Barold ${ }^{1}$, James D. Maloney², Bengt Herweg ${ }^{3}$ \\ ${ }^{1}$ Florida Heart Rhythm Institute, Tampa, Florida, USA \\ ${ }^{2}$ Private Practice, Sarasota, Florida, USA
}

\begin{abstract}
Electrocardiographic artifacts may generate recordings mimicking supraventricular and ventricular tachyarrhythmias. This report describes the diagnostic challenge presented by Holter or loop recordings in two patients, one with pseudo-atrial flutter and the other with pseudo-polymorphic ventricular tachycardia. (Cardiol J 2013; 20, 1: 106-109)
\end{abstract}

Key words: electrocardiography, loop recording, artifactual tachyarrhythmia, atrial flutter, ventricular tachycardia

\section{Introduction}

Electrocardiographic (ECG) artifacts which are usually caused by loose electrodes or body movement may generate recordings mimicking supraventricular and ventricular tachyarrhythmias. The distinction of artifactual tachyarrhythmias from true arrhythmias is not always easy especially in Holter or external loop recordings because of the limited number of recording leads. This report describes the diagnostic challenge presented by Holter and external loop recordings in two patients, one with pseudo-atrial flutter (AFl) and the other with pseudo-polymorphic ventricular tachycardia (VT).

\section{Case 1}

Figures 1 and 2 show recordings from a 3 channel Holter recorder obtained from a 45 year-old patient with vague dizziness and no tremor or other pertinent history. The diagnosis made by two cardiologists was rapid type II AFl with a suggestion that catheter ablation might be appropriate. The atrial rate was estimated at $420 \mathrm{bpm}$ certainly com-

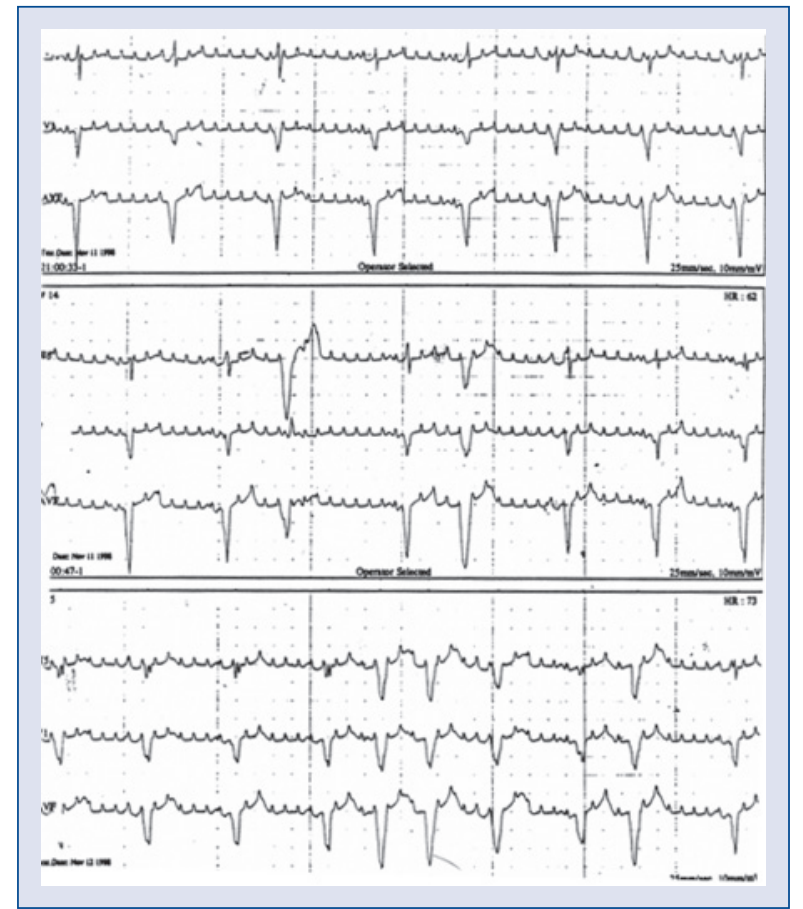

Figure 1. Pseudo-atrial flutter recorded in by 3 channel Holter monitor. See text for details.

Address for correspondence: S. Serge Barold, MD, Florida Heart Rhythm Institute, Tampa, Florida, USA, tel: 8138911922 , e-mail: ssbarold@aol.com 


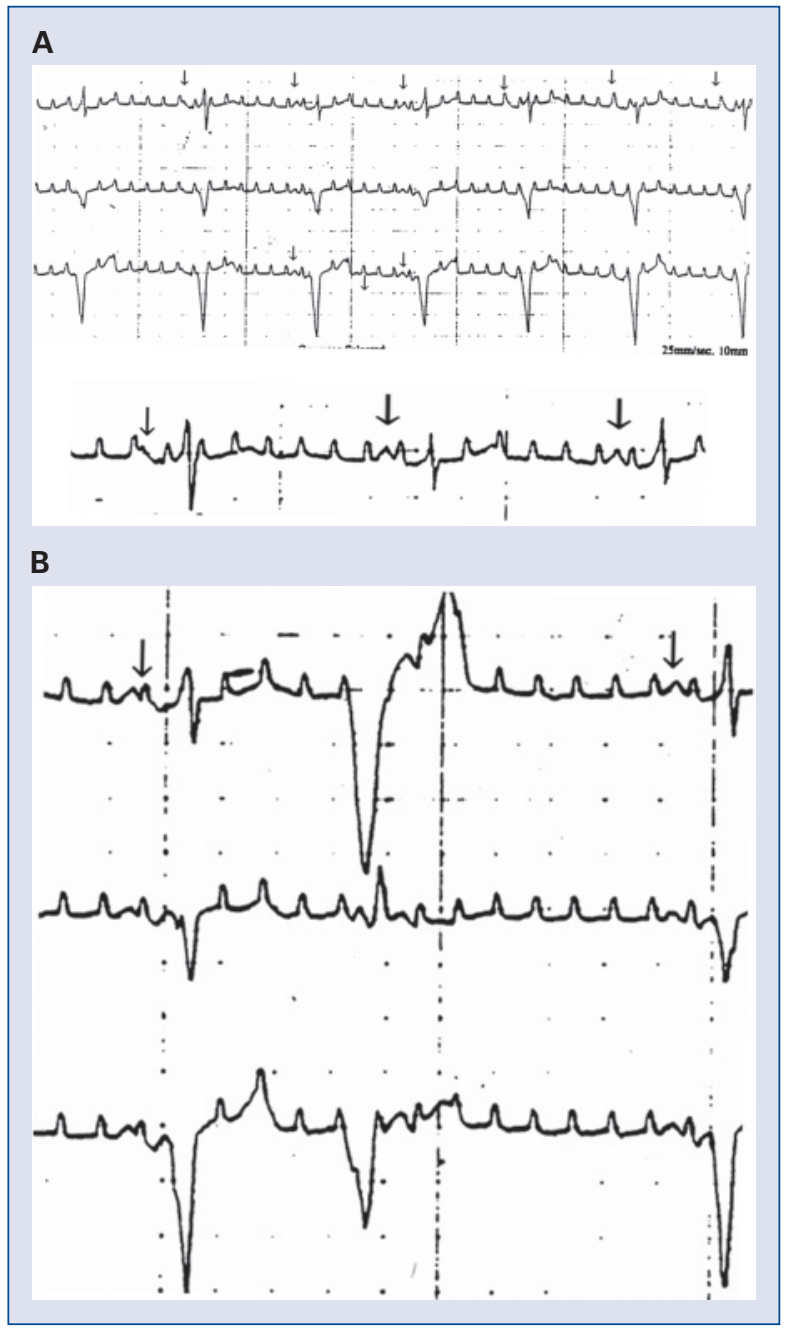

Figure 2. A. Top panel from Figure 1 and magnified portion of the top strip from this panel. The arrows point towards P waves. See text for details; B. Magnified portion of the top strip in the middle panel of Figure 1. The arrows point towards $\mathrm{P}$ waves. See text for details.

patible with type II AFl. The presence of artifacts was initially not recognized because the rapidly occurring "atrial" deflections were regular and considered to represent a well-organized "atrial" rhythm. However, further analysis of the tracings revealed the presence of an underlying sinus rhythm hidden by artifactual or pseudo-F waves (Figs. 1, 2). The tracings do not show the features of "atypical" or type II AFl because of the relatively long isoelectric segment between the pseudo-F waves which exhibit a configuration not usually seen in type II AFl.

\section{Case 2}

A 39 year-old woman presented with supraventricular tachycardia and a history of palpitations,

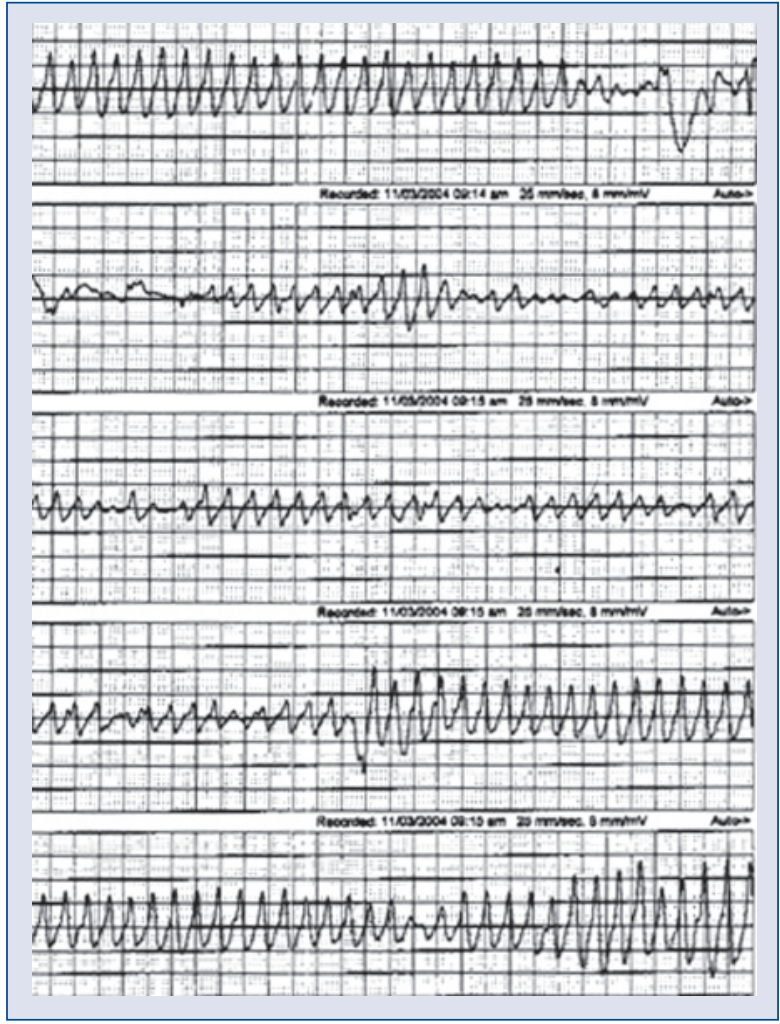

Figure 3. Pseudo-polymorphic ventricular tachycardia recorded in an external loop recording. See text for details.

lightheadedness and near syncope. She underwent ablation of a slow-slow atrio-ventricular nodal tachycardia and ablation of a bystander accessory pathway. A couple of days later an external loop recording was obtained because of vague dizziness (Fig. 3). The patient experienced vague lightheadedness during the recording which was not correlated with the tracing in Figure 3. There was no contact with a cellular phone or magnetic resonance imaging. The primary cardiac electrophysiologist was out-of-town and another board-certified cardiac electrophysiologist made the diagnosis of polymorphic VT and recurrence of bypass anterograde conduction. A second electrophysilogic study was performed and a posteroseptal accessory pathway was ablated. An aggressive VT stimulation protocol (3 stimuli and isuprel) was negative. A thallium stress test and a challenge with intravenous procainamide was negative for Brugada syndrome. After the second electrophysiologic study the second electrophysiologist made arrangements for the implantation of a implantable cardioverter-defibrillator (ICD) based on the belief that Figure 3 was not artifactual. The primary cardiac electrophysiologist returned only a few hours before the sched- 
uled ICD surgery. The tracings were then evaluated by 3 cardiac electrophysiologists who made the diagnosis of artifactual polymorphic VT. The patient has remained well for over 7 years.

\section{Discussion}

The diagnosis of any tachyarrhythmias should always include ruling out the possibility of an artifactual recording. With regard to the diagnosis of pseudo-tachyarrhythmias, Knight et al. wisely stated that "what you do not look for, you will not recognize" [1-3].

\section{Pseudo-atrial flutter}

Regarding the terminology of $\mathrm{AFl}$, the new classification of $\mathrm{AFl}$ based on mechanisms does not include terms such as type I and type II flutter because the mechanism of type II flutter is not fully understood [4-6]. Terms like uncommon or atypical flutter to describe forms of type II have been abandoned. Yet, the original classification of AFl into type I and II remains commonly used clinically [4]. Thus, the diagnosis of type II AFl in our case by general cardiologists is not surprising and likely to continue.

Wells et al. [4] in 1979 classified AFl into two types: type I (usual) and type II (very rapid). Type I could be entrained and interrupted by atrial pacing but type II AFl could not probably because of the lack of an excitable gap. These 2 types of AFl can be distinguished on the basis of rate. Type I AFl in the absence of drug therapy type I has a rate of 240 $-340 \mathrm{bpm}$ and type II AFl has a rate of 340-430 bpm. In our patient, an artificial atrial rate of $420 \mathrm{bpm}$ was compatible with the diagnosis of type II AFl. There is probably overlap of the upper of type I AFl with the lower rate of type II AFl. Type II AFl constitute an heterogeneous group of arrhythmias that are transitional to atrial fibrillation (AF). Thus, they behave more like AF than common AFl. Type II AFl may occur as an unstable rhythm when overdrive atrial pacing is used to terminate type $\mathrm{IAFl}$ whereby acceleration of the atrial rate and a change of atrial activation may occur. Type II AFl tends to occur after a cardiac procedure such as surgery or ablation for AF. Type II AFl presents a variable ECG pattern with no characteristic manifestation.

Artifactual ECGs of supraventricular tachyarrhythmias are well-documented. They include tracings simulating supraventricular tachycardia, $\mathrm{AFl}, \mathrm{AF}$ and $\mathrm{AFl} / \mathrm{AF}$ with potential disastrous consequences if anticoagulant therapy is administered [7-14].
Parkisonian tremor may cause pseudo-AFl but the diagnosis is easy by finding an ECG lead with a normal $\mathrm{P}$ wave $[7,10,11]$. Furthermore the baseline disturbance is often irregular in contrast to our case where the baseline disturbance was absolutely regular.

\section{Pseudo-polymorphic ventricular tachycardia}

Pseudo-VT has been amply documented in the literature $[2,3,15-20]$. In our case one could interpret the tracing as showing fast organized ventricular flutter alternating with ventricular fibrillation (VF) which then reorganized itself back into ventricular flutter. One would have to postulate that this mechanism occurred several times in the recording. This scenario is highly unlikely because such alternation between VF and VT does not seem to occur clinically. During what appears to be rapid sustained VT some of the R-R intervals measured $160 \mathrm{~ms}$ which makes ventricular flutter highly unlikely at a rate $>300 \mathrm{bpm}$. Correlation with the lack of symptoms during the loop recording makes the possibility of a true VT (300 bpm or faster) highly unlikely. We made the diagnosis of pseudo-VT based on a constellation of observations that favored artifact rather than a specific findings that facilitate the diagnosis of pseudo-VT. These include the "notch" sign superimposed on the wide complexes (corresponding to the sinus rate), the "spike" sign and, or the presence of visible sinus rhythm ( $\mathrm{P}$ waves) in one frontal lead as in tremor-induced pseudo-VT $[18,19]$.

\section{Conflict of interest: none declared}

\section{References}

1. Stevenson WG, Maisel WH. Electrocardiography artifact: What you do not know, you do not recognize. Am J Med, 2001; 110: 402-403.

2. Knight BP, Pelosi F, Michaud GF, Strickberger SA, Morady F. Physician interpretation of electrocardiographic artifact that mimics ventricular tachycardia. Am J Med, 2001; 110: 335-338.

3. Knight BP, Pelosi F, Michaud GF, Strickberger SA, Morady F. Clinical consequences of electrocardiographic artifact mimicking ventricular tachycardia. N Engl J Med, 1999; 341: 1270-1274.

4. Wells JL Jr, MacLean WA, James TN, Waldo AL. Characterization of atrial flutter. Studies in man after open heart surgery using fixed atrial electrodes. Circulation, 1979; 60: 665-673.

5. Saoudi N, Cosío F, Waldo A et al.; Working Group of Arrhythmias of the European of Cardiology and the North American Society of Pacing and Electrophysiology. A classification of atrial flutter and regular atrial tachycardia according to electrophysiological mechanisms and anatomical bases; a Statement from a Joint Expert Group from The Working Group of Arrhythmias 
of the European Society of Cardiology and the North American Society of Pacing and Electrophysiology. Eur Heart J, 2001; 22: 1162-1182.

6. Scheinman MM, Yang Y, Cheng J. Atrial flutter: Part II. Nomenclature. Pacing Clin Electrophysiol, 2004; 27: 504-506.

7. Baranchuk A, Shaw C, Alanazi H et al. Electrocardiography pitfalls and artifacts: The 10 commandments. Crit Care Nurse, 2009; 29: 67-73.

8. Jadidi AS, Sunthorn H, Burri H, Gentil-Baron P, Shah D. Is this atrial fibrillation? Ann Noninvasive Electrocardiol, 2009; 14: 96-98.

9. Rowlands DJ, Moore PR. Spurious atrial tachycardia in a pilot. Prediction of the artifactual appearances in all twelve leads, when a single limb lead is the source of the artifact. J Electrocardiol, 2007; 40: 475-477.

10. Baranchuk A, Kang J. Pseudo-atrial flutter: Parkinson tremor. Cardiol J, 2009; 16: 373-374.

11. Prabhavathi B, Ravindranath KS, Moorthy N, Manjunath CN. Pseudo-atrial flutter/fibrillation in Parkinson's disease. Indian Heart J, 2009; 61: 296-297.

12. Finsterer J, Stöllberger C, Gatterer E. Oral anticoagulation for ECG tremor artefact simulating atrial fibrillation. Acta Cardiol, 2003; 58: 425-429.
13. Austin SM, Flach SD, Gaines CM. Atrial flutter simulated by a portable compact disk player. Mayo Clin Proc, 2007; 82: 383-384.

14. Davidenko JM, Snyder LS. Causes of errors in the electrocardiographic diagnosis of atrial fibrillation by physicians. J Electrocardiol, 2007; 40: 450-456.

15. Hoffmayer KS, Goldschlager N. The utility of the "notch" sign. J Electrocardiol, 2009; 42: 57.

16. Hoffmayer KS, Goldschlager N. Pseudoatrial flutter. J Electrocardiol, 2008; 41: 201.

17. Davis E, Hoffmayer K, Turakhia M, Goldschlager N. Polymorphic ventricular tachycardia? J Hosp Med, 2009; 4: 140$-141$.

18. Tarkin JM, Hadjiloizou N, Kaddoura S, Collinson J. Variable presentation of ventricular tachycardia-like electrocardiographic artifacts. J Electrocardiol, 2010; 43: 691-693.

19. Huang CY, Shan DE, Lai $\mathrm{CH}$ et al. An accurate electrocardiographic algorithm for differentiation of tremor-induced pseudoventricular tachycardia and true ventricular tachycardia. Int J Cardiol, 2006; 111: 163-165.

20. Vereckei A. Pseudo-ventricular tachycardia: Electrocardiographic artifact mimicking non-sustained polymorphic ventricular tachycardia in a patient evaluated for syncope. Heart, 2004; 90: 81. 